\title{
Effects of Methanol Extract of Securidacalongepedunculata on Haematology and Histology of Rats
}

\author{
${ }^{1}$ Abonyi O., ${ }^{1}$ Uzoegwu P.N., ${ }^{1}$ Ezugwu A. L., ${ }^{1}$ Ani C.C., ${ }^{1}$ Uroko R. I., \\ ${ }^{1}$ Onyemuche, T. N.and ${ }^{2}$ Anigbogu J.U. \\ ${ }^{1}$ Department of Biochemistry, University of Nigeria, Nsukka, Nigeria. \\ ${ }^{2}$ Department of Biochemistry, Tansian University Umunya, Nigeria.
}

\begin{abstract}
Thirty -two (32) wistar rats were divided into four groups of eight. Group one was given $5 \mathrm{ml} / \mathrm{kgbw}$ of normal saline and it served as the control, while groups two to four were given 100, 200 and $500 \mathrm{mg} / \mathrm{kgbw}$ of methanol extract Securidacalongepedunculata for twenty-eight (28) days. All the rats were maintained ad libitum on chick's mash and water. Sacrifices were done on the $7^{\text {th }}, 14^{\text {th }}, 21^{\text {st }}$ and $28^{\text {th }}$ day for the haematology and the histological examination was after the $28^{\text {th }}$ day. The result showed a significant $(p<0.05)$ decrease in $H b$ concentration and WBC when compared to the control at weeks one (acute phase) and four (chronic phase). Weeks two and three showed variations. The same trend was seen in packed cell volume (PCV) with exception in group four of week four. On examination of the organs, there was no morphological difference, however, there were histological changes in the liver and kidneys of animals treated with the extract. These changes were characteristically severe degeneration/necrosis, severe congestion, lymphocytes infiltration, sinusoid enlargement and parenchyma hypertrophy. These results seemed to suggest haemolytic effect and significant organ damage of the methanol extract of Securidacalongepedunculataat the chronic phase.
\end{abstract}

Key words: Securidacalongepedunculata, haematology, histological examination, rats

\section{Introduction}

Phytomedicinal research of indigenous plant parts is presently gaining more grounds than ever as the majority of people are now patronizing herbal medicinal treatment which is considered to be more easily accessible and cheaper than orthodox medical treatment (Ajiboyeet al., 2010). The usefulness of medicinal plants is directly linked to the wide range of chemical compounds synthesized in various biochemical pathways; which are classified as secondary metabolites. (Ameyaw and Duker-Eshun 2009). The medicinal value of these plants lies in some chemical substances that produce a definite physiological action on the human body (Edogaet al., 2005; Lavanyaet al., 2007)

Securidacalongepedunculata family polygalaceae is a tropically distributed medicinal plant (Mohammed, et al 2012). It is widely distributed in West African and South African regions (Abdullahi and Lawal, 2010). The plant is known as Rhodes' violet wild vesteria (English), uwarmagunguna (Hausa) and Atumaka (Ibo). It is also used in bacterial chemotherapy (Akinniyiet al., 1996; Mohammed et al., 2012). The plant is also used in the treatment of cough, headache, constipation, wound, sore throat and gout (Ojewale, 2008). Its anti-snake venom potential has also been reported (Wannaget al., 2005). Some secondary metabolite contents such as alkaloids and flavonoids and related compounds such as methyl salicylate has been reported (Iddagoda and Thamara, 2003; Abdullahi and Lawal, (2010). The cytotoxicity of the plant was reported (Abdullahi and Lawal, 2010). Signs of toxicity and death was also reported following intraperitoneal administration of $100 \mathrm{mg} / \mathrm{kgbw}$ (Dapar, et al 2007). Etuk, et al (2006) reported that there was no sign of toxicity following oral administration after 28 days.

One of the pronounced challenges in the utilization of herbal remedies is in the areas of standardization, pharmacological and toxicological profiles of some of the plants (Oliver, 1980 and Iwu, 1982). Extraction of bioactive compounds from medicinal plants permits the demonstration of their physiological activity. It facilitates pharmacological studies and leads to the synthesis of pure and potent compounds with decreased toxicity (Abdullahi and Lawal, 2010). This study was, therefore, aimed at investigating the effect of Securidacalongepedunculata on haematological parameters and the histology of the liver and kidneys with the view to elucidating any possible toxicity of the extract on the blood cells and these organs. This will attempt at giving more scientific backing on the toxicology of this plant that has seemingly contradicting reports for a better pharmacological knowledge of the extract in order to minimize toxicity. 


\section{Materials and Methods}

Animals: The animals used in this study were adult wistar rats. They were obtained from the animal house of Department of Zoology and Environmental Biology, University of Nigeria Nsukka, equilibrated and fed with chick's mash and water for 28 days.

Plant materials:The leaves of Securidacalongepedunculata were collected from OpiNsukka and identified by Mr Alfred Ozioko of Bioresources Diversity and Conservative Programme (BDCP) Nsukka. The leaves were air-dried and pulverized.

Experimental Design: Thirty-two rats were grouped into four groups of eight rats each as follows: Group 1 control (received normal saline and normal feed orally). Group 2 was fed with $100 \mathrm{mg} / \mathrm{Kgbw}$,group 3 was fed with $200 \mathrm{mg} / \mathrm{Kgbw}$ while group 4 received $500 \mathrm{mg} / \mathrm{Kgbw}$ of methanol extract ofS. longepedunculata. The feeding was by intubation (oral feeding).Two rats from each group were sacrificed on the $7^{\text {th }}, 14^{\text {th }}, 21^{\text {st }}$ and $28^{\text {th }}$ days and the tissues and the blood collected and prepared for different assays.

Histology: The organ specimen (kidneys and liver) were removed from the visceral cavity and fixed with formalsaline (10\% formaladehyde in normal saline). They were allowed to stay for 3-4 days in 10 times (10x) the volume of the specimen. Dehydration followed using ethanol. The alcohols were changed after steeping the organs in them for 1.5-2 hrs. the organs were cleared in chloroform and impregnated with paraffin wax and sectioned at 5 micros thickness using rotary microtome. The sections were floated on a water bath maintained at 2-3 ${ }^{\circ} \mathrm{C}$ above the mid point of the paraffin wax used. When dried (15-30 mins) they were stained with haematoxylin and eosin (H\& E), dehydrated, cleared and mounted. Magnification of 400 was employed.

\section{Results and Discussion}

The packed cell volume (PCV) result showed a significant decrease $(\mathrm{P} \leq 0.05)$ at weeks one, two and four (with exception of group 4 week four). Weeks three showed a significant increase ( $\mathrm{P} \leq 0.05)$ (Fig.1) suggesting a low glucose level within those periods and an ample glucose level in week three.Since red cells depend on glucose for its glycolysis, this decrease in packed cell volume, ultimately, could affect the rate of oxygen and nutrient transport at acute and chronic phases since red blood cells are involved in transport of oxygen. The haemoglobin $(\mathrm{Hb})$ concentration, further confirmed this. There was a general reduction in $\mathrm{Hb}$ concentration at these acute and chronic phases (Fig.2) suggesting a haemolytic damage to red blood cells at this period. Patients, whose kidneys no longer secrete sufficient levels of the hormone erythropoietin that promotes red blood cells proliferation suggest compromise on the integrity of the kidney cells (Jelkmann, 2004)(erythropoietin prevents the death of cells in the erythrocyte cell line in the bone marrow). The white blood cells' result suggested immunosuppression at chronic phase of the experiment (Fig.3).

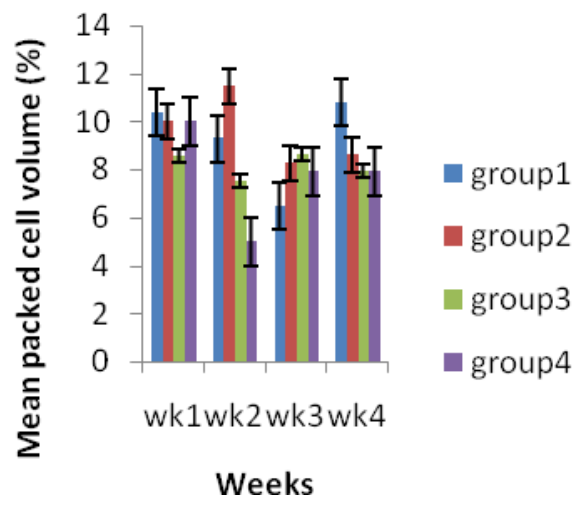

Fig.1 Effect of MESL on packed cell volume (PCV) of albino rats 


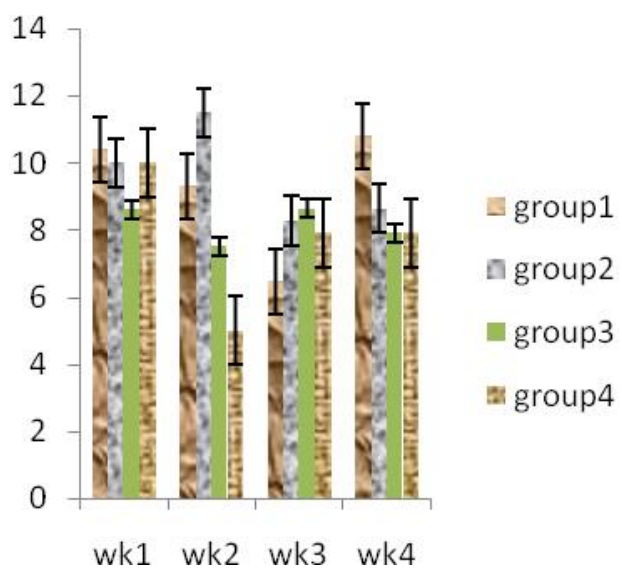

Fig.2 Effect of MESL on haemoglobin concentration of albino rats

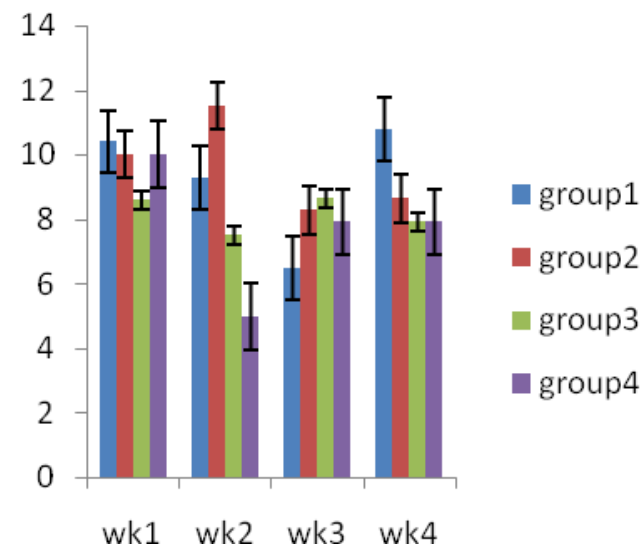

Fig.3 Effect of MESL on white blood cells count (WBC) of albino rats

The histopathology result showed various effects on the organs; liver and kidneys. A severe cellular infiltration and lymphocyte hypertrophy were observed in the liver of rats fed with 100 and $200 \mathrm{mg} / \mathrm{kgbw}$ (Plates 3 and 5) compared to the control (Plate 1). The kidneys of rats fed with 100, 200 and $500 \mathrm{mg} / \mathrm{kg}$ bw showed a severe degeneration of glomerular filtrate and sever epithelial necrosis when compared to the control group that was intact (Plates 4, 6 and 2). Sinusoid enlargement was observed in the liver of $500 \mathrm{mg} / \mathrm{kg} \mathrm{bw}$ fed rats as compared to the control group that was intact (Plates 8 and 1). The examination was done after 28 days. These injuries on the liver and kidneys might be because of the duration of the administration and the dosage employed suggesting a distortion in structure and function of these organs. This might be as a result of toxic effect of the extract at this chronic phase. The severe degeneration of glomerular content as seen in the histology of the kidney, could be as a result of a possible distortion in re-absorption/ultra-filtration efficacy of the glomerulus, while the epithelial necrosis seemed to indicate a membrane destabilization which might have ultimately affected the integrity of the mitochondrial membrane causing a distortion of the protomotive gradient necessary for ATP synthesis. Oxidative stress is a critical event in the opening of mitochondrial membrane permeability transition pores and the breakdown of the mitochondrial membrane potential (Konet al., 2001; Reid et al., 2005) which leads to ATP depletion and cell death by oncotic necrosis (Gujralet al., 2002), hence the necrosis observed. Sinusoid is a dilated channel into which arteries or veins open which takes the place of the usual capillaries. The sinusoid enlargement observed, therefore, could lead to hypotension. Researchers, also observed cytotoxicity of the root bark extract of the plant on Artemisia salina. They also observed that the toxic activity of the plant extract decreased with increase in polarity of solvent (Abdullahi and Lawal, 2012). These findings were evident in terms of the polarity of compound extracted by each solvent in addition to their intrinsic bioactivity. In addition, it was reported that intraperitoneal administration of $100 \mathrm{mg} / \mathrm{kg}$ bw of the root extract of Securidacalongepedunculataresulted in signs of toxicity and death in rats (Daparet al, 2007). 


\section{Conclusion}

Varied reports have been presented on the toxicity of Securidacalongepedunculata. The present study has lent its own finding which seemed to suggest that there might be a level of organ damage. This should be taken into cognizance in the use of the plant for medicinal purposes as a negligence might be deleterious especially at the chronic phase.

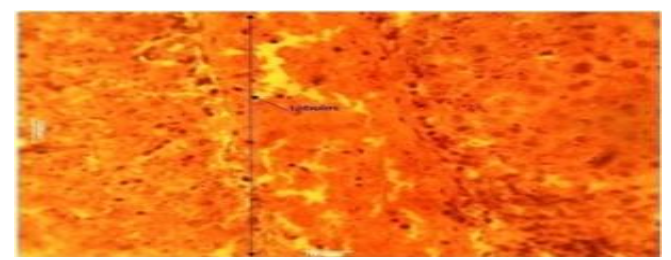

Plate 1 Photomicrograph of normal morphology of liverlobules of group 1 (control)

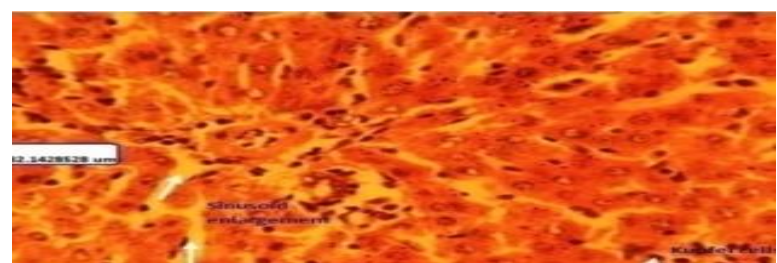

Plate 2: The photomicrograph of the liver of group $2(100 \mathrm{mg} / \mathrm{kgbw})$ with severe cellular infiltration and lymphocytes hypertrophy

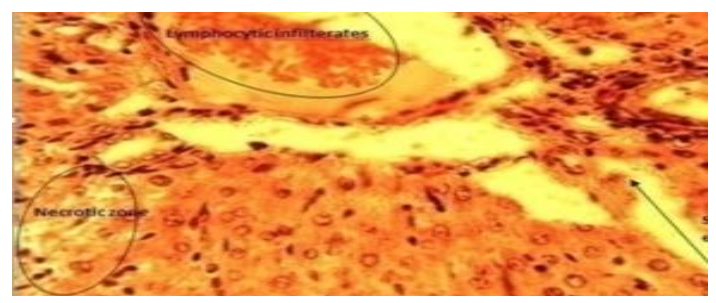

Plate 3 Photomicrograph of the liver of group 3 rat showing severe passive congestion around the central veins

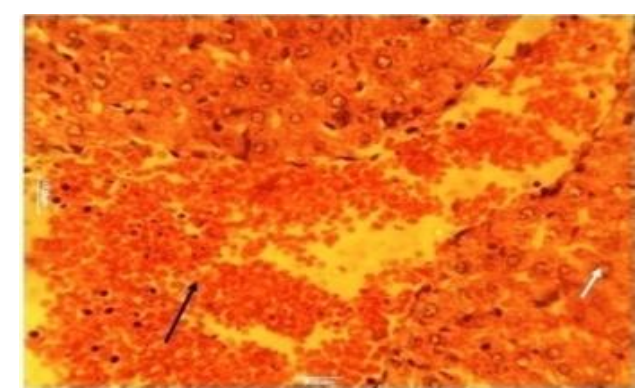

Plate 4: The photomicrograph of the liver of group 4 ratfed with $500 \mathrm{mg} / \mathrm{kgbw}$ showing a sinusoid enlargement

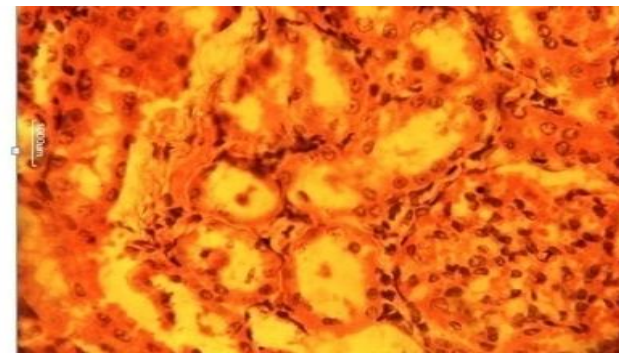

Plate 5 Photomicrograph of intact glomerular contents of the kidney of group 1 (control) 


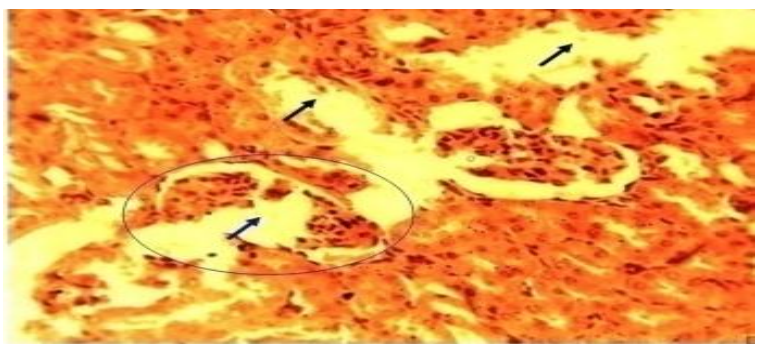

Plate 7 Showing the photomicrograph of the rat kidney in group $3(200 \mathrm{mg} / \mathrm{kg}$ bw). Tubular epithelial cell degeneration and necrosis characterize the cells.

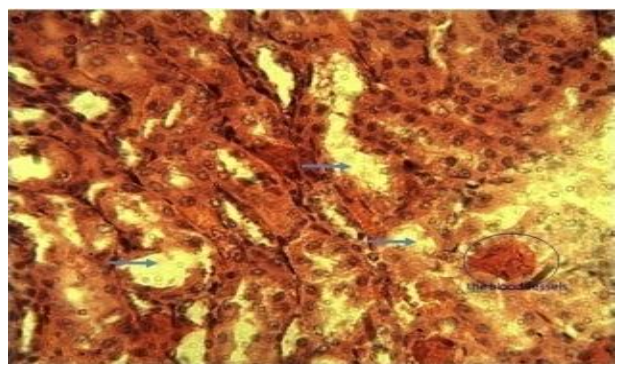

Plate 6 showing the photomicrograph of the kidney of group $2(100 \mathrm{mg} / \mathrm{kgbw})$ rat with severe degeneration of glomerular content and severe epithelial necrosis

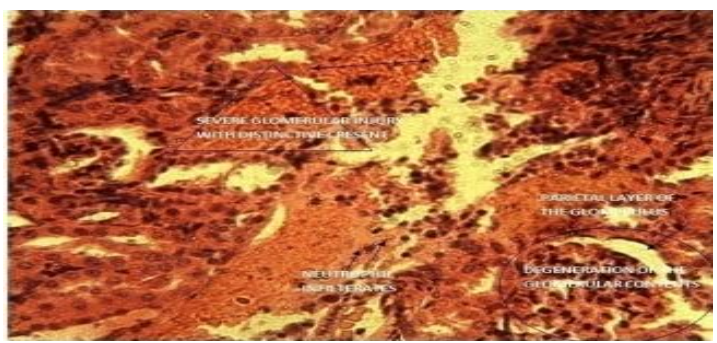

Plate 8Representing the photomicrograph of the kidney of group 4 rat with progressive mesangial proliferation, neutrophils infiltrates, degeneration of glomerular content and enlargement of the glomeruli, dominate the micrograph.

\section{REFERENCES}

[1]. Abdullahi, S.K. and Lawal, G.H.(2010).Antibacterial Screening and Brine Shrimp (Artemia $\quad$ salina) Toxicity of Securidacalongepedunculata (Polygalaceae) Root Bark. African Journal of Pharmaceutical Sciences, 1:85-95

[2]. Ajiboye, T.O., Salau, A.K., Yakubu,M.T.,Oladiji,A.T., Akanji,M.A. and Okokun J.I.(2010.). $\quad$ Imbalance in Male Rat Liver and Kidney. Human and Experimental Toxicology, 29(8):679-688.

[3]. Akinniyi,J.A., Manawadu, D. and Sultanbawa, M.(1996).Ethnobotany and Ethnopharmacologyof Nigerian Medicinal Plants Research Traditional Medicine in Malaria.

[4]. Ameyaw, Y. and Duker-Eshun, G. (2009). The alkaloid contents of the ethno-plant organs of $\quad$ three anti malarial medicinal plant species in the eastern region of Ghana. International

[5]. Journal of ChemicalScience, 7 (1): 48-58.

[6]. Dapar, L. P. M., Aguiyi, C. J., Wannang, N. N., Gyang, S. S. and Tanko, M. N. (2007). The histopathologic effects of Securidacalongepedunculata on heart, liver, kidney and lungs

[7]. of rats. African Journal of Biotechnology,6: 591-595.

[8]. Edoga H.O. Okwu, D.E. and Mbaebie, B.O. (2005). Phytochemical constituents of Nigerian medicinal plants. African Journal of Biotechnology,4(7): 685-688.

[9]. Etuk, E. U., Adebiyi, R. A., Elsa, A. T. and Agaie, B. M. (2006). Acute and subchronic oral toxicity studies of the aqueous root extract of SecuridacalongepedunculataFresen (Polygalaceae) in mice. International Journal of Pharmacology, 2: 421-425.

[10]. Iddagoda, L. and Thamara, K.J.D.(2003).Phytochemical studies of Securidaca longepedunculataand its use as a deterrent against stored grain insect pests. A Thesis Submitted inFulfilment of the Requirement of the University of Greenwich for the

Degree of Doctorof Philosophy.

[11]. Iwu, M.M. (1982). Perspectives of Igbo tribal ethnomedicine, Cecta, Enugu, Pp 4-5.

[12]. Jelkmann, W. (2004). Molecular biology of erythropoietin. Internal Medicine,43: 649-659.

[13]. Lavanya, R., JairamV ., Sudhakar c. Stephen H.S. and Millar Jnr J . C (2007). Anthocyanin fraction from potato extracts is cytotoxic to prostate cancer cells through activation of caspase- dependent and caspase- independent pathways. Carcinogenesis,2B (10): 2227-

[14]. 2235 .

[15]. Ojewole, J. A. O. (2008). Analgesic, anti-inflammatory and hypoglycaemic effects of (Polygalaceae) root bark aqueous extract. Inflammapharmacology, 15: 174-181. 
[16]. Oliver, B. (1980). Medicinal plants in Nigeria: Nigerian College of Arts, Sciences and Technology, Ibadan. Pp.94-95.

[17]. Mohammed, A.,Ndamitso,M.M. and Aisha,R.S.(2012.).Phytochemical and, Antibacterial activity of

Securidacalongepedunculata on selected pathogens. Prime Research on Medicine,2(3):89-934

[18]. Wannag, N.N., Wudil,A.M., Dapar, L.M.P. and Bichi, L.A.(2005). Evaluation of anti-snake venom activity of the aqueous root extract of Securidacalongepedunculatain rats. JounalofPharmacologyand Biological Research,2:80-83. 